\title{
Advantages of Integrated and Sustainability based Assessment for Metabolism based Strategic Planning of Urban Water
}

\section{Systems}

\author{
Kourosh Behzadian $^{\mathrm{a}, *}$ and Zoran Kapelan ${ }^{\mathrm{a}}$ \\ ${ }^{a}$ Centre for Water Systems, College of Engineering, Mathematics and Physical Sciences, \\ University of Exeter, North Park Road, Harrison Building, Exeter, EX4 4QF, UK
}

\section{Abstract}

Despite providing water-related services as the primary purpose of urban water system (UWS), all relevant activities require capital investments and operational expenditures, consume resources (e.g. materials and chemicals), and may increase negative environmental impacts (e.g. contaminant discharge, emissions to water and air). Performance assessment of for such a metabolic system may require developing a holistic approach which encompasses various system elements and criteria. This paper analyses the impact of integration of UWS components on the metabolism based performance assessment for future planning using a number of intervention strategies. It also explores the importance of sustainability based criteria in the assessment of long-term planning. Two assessment approaches analysed here are: (1) planning for only water supply system (WSS) as a part of the UWS and (2) planning for an integrated UWS including potable water, stormwater, wastewater and water recycling. WaterMet ${ }^{2}$ model is used to simulate metabolic type processes in the UWS and calculate quantitative performance indicators. The analysis is demonstrated on the problem of strategic level planning of a real-world UWS to where optional intervention strategies are applied. The resulting performance is assessed using the multiple criteria of both conventional and sustainability type; and optional intervention strategies are then ranked using the Compromise Programming method. The results

\footnotetext{
* Corresponding author. Tel.: +44 (0)1392 724075; fax: +44 (0)1392 217965.

E-mail address: k.behzadian-moghadam@exeter.ac.uk (K. Behzadian), z.kapelan@exeter.ac.uk (Z. Kapelan).
} 
obtained show that the high ranked intervention strategies in the integrated UWS are those supporting both water supply and stormwater/wastewater subsystems (e.g. rainwater harvesting and grey water recycling schemes) while these strategies are ranked low in the WSS and those targeting improvement of water supply components only (e.g. rehabilitation of clean water pipes and addition of new water resources) are preferred instead. Results also demonstrate that both conventional and sustainability type performance indicators are necessary for strategic planning in the UWS.

Keywords: Urban water; water supply; integrated system; sustainability; multi-criteria assessment; performance indicator;

\section{Abbreviations}

BAU: business as usual $\mathrm{CP}$ : compromise programming CSO: combined sewer overflow D: water demand DM: distribution main GHG: greenhouse gas GWR: greywater recycling KPI: key performance indicator MCM: million cubic metres O\&M: operations and maintenance POP: population RWH: rainwater harvesting S: water supply SC: subcatchment SN: sewer network SR: service reservoir TM: trunk main RW: receiving water RWH: rainwater harvesting WR: water resource WSC: water supply conduit WSS: water supply system WTW: water treatment works WWTW: wastewater treatment works UWS: urban water system

\section{Introduction}

Urban water system (UWS) is typically applied to description of the three main subsystems of drinking water supply, stormwater and wastewater collection (Loucks et al., 2005). Assessment of each subsystem separately for particular purposes is a traditional approach which can be done by using physically based models such as the EPANET model to simulate hydraulic and water quality-water quality behaviour of water distribution systems (Rossman, 2000) and the SWMM model to simulate 
hydrology-hydraulic behaviour of urban drainage and sewer networks (Rossman, 2010). However, impact assessment of the UWS performance on urban sustainable development would require a more integrated approach for modelling UWS components (Makropoulos et al., 2008).

This aim for assessing the UWS performance can be achieved by conceptually-based models which are able to capture the complex interrelations and interactions between the UWS subsystems (Savic et al., 2013). These models have been widely developed to fulfil the requirements of integrated modelling for assessment of various UWS components and subsystems such as water supply (Sušnik et al., 2012; Collet et al., 2013), drainage or combined sewerage (Fu et al., 2009) and integrated UWS (Makropoulos et al., 2008; Mackay and Last, 2010; Mitchell and Diaper, 2010; Fagan et al., 2010; Willuweit and O’Sullivan, 2013; Behzadian et al., 2014a, Venkatesh et al., 2014, Villarroel Walker et al., 2014; Behzadian and Kapelan 2015). These models mainly evaluate urban water-related services as the primary aim of performance metrics and thus are limited to the conventional performance indicators. Some models deal with only water quantity-related metrics (e.g. Sušnik et al., 2012) or water quantity and quality (e.g. Fu et al., 2009) or water-energy nexus (e.g. Makropoulos et al., 2008; Mackay and Last, 2010; Mitchell and Diaper, 2010). A literature review conducted by Nair et al. (2014) reveals that integrated UWS modelling through a systematic framework is necessary to capture the dynamics of multiple water-energy-greenhouse gas (GHG) linkages within their components. The performance metrics related to water-energy-GHG nexus have also been provided by some integrated UWS models (e.g. Fagan et al., 2010; Behzadian et al., 2014b). However, the impact of urban water cycle on other sustainability dimensions such as socio-economic factors and environmental impacts are often overlooked (Huang et al., 2013). This multi-dimensional impact on the UWS performance can be envisaged by means of a metabolism concept for input, output fluxes and other processes in between (Venkatesh et al., 2014; Behzadian and Kapelan, 2015).

The concept of UWS metabolism is driven from definition of urban metabolism as "the sum total of the technical and socio-economic processes that occur in cities, resulting in growth, production of 
energy, and elimination of waste" (Kennedy et al., 2007). The literature review conducted by Kennedy et al. (2011) manifested the importance of urban water-related fluxes in an urban metabolism analysis. In addition, while water is one of the four major components of urban metabolism (water, food, construction materials, and energy) identified by Baccini and Brunner (1991), urban water cycle can influence materials and energy in urban metabolism. In fact, the urban water cycle is a set of various services resembling a human metabolic system (Huang et al., 2013). The UWS metabolism implies a variety of required flows and fluxes (e.g. water, materials, chemicals and cost) to provide UWS services which consequently generate a number of other fluxes (e.g. GHG emissions, acidification and contamination discharge to air and water). Similar to other urban metabolic systems, the UWS metabolism is influenced by and has considerable impacts on other spheres such as social, economic and environmental. Understanding of these impacts is particularly important because this can affect the selection of appropriate interventions including both operational strategies and new infrastructure. All this requires a modelling approach for metabolism based assessment of the UWS performance.

Although numerous UWS models have been developed as listed above in the recent decades, the metabolism based UWS performance was addressed by only a few of them which are briefly discussed here. Fagan et al. (2010) presented a dynamic metabolism model which can provide a comprehensive set of metrics related to sustainability and cost effectiveness in the UWS. Huang et al. (2013) developed a conceptual metabolism model for integrated analysis of both real and virtual water in the UWS. The $D M M$ and WaterMet ${ }^{2}$ models are two different metabolism based models developed respectively by Venkatesh et al. (2014) and Behzadian and Kapelan (2015) under the EU TRUST (TRansition to sustainable Urban Systems of Tomorrow) project (Behzadian et al., 2014a). Although both models quantify a number of performance indicators related to various dimensions of future sustainability, the functionality of these two models is quite different. The DMM is a lumped metabolism model based on annually-aggregated of water flows within the entire UWS; hence, fluxes of water-related resources and other environmental impacts are quantified by multiplying annual water flow by a suitable conversion 
factor (Venkatesh et al., 2015). However, WaterMet ${ }^{2}$ is a distributed metabolism model which simulates water related and other resources flows throughout the UWS components with a higher resolution both spatially (e.g. multiple water resources and service reservoirs) and temporally (e.g. daily and monthly) (Venkatesh et al., 2015). The difference of functionality in these models has caused intervention strategies are simulated differently in these models and due to this, some optional interventions cannot be modelled using the DMM such as water recycling schemes and leakage. Villarroel Walker et al. (2014) also presented a MSA (Multi-sectoral Systems Analysis) tool which explores the impact of water-related strategic technologies on urban metabolism using systems analysis.

Furthermore, each potential and complex intervention in the UWS can result in specific performance and environmental impacts which can be quantified by a metabolism based analysis or other tools. As such, various dimensions of the UWS sustainability may be affected by these impacts (Alegre et al., 2012). Therefore, an overarching analysis of various interventions necessitates considering a multicriteria performance assessment framework which can be linked to the simulation model (Chrysoulakis et al., 2013; Morley et al., 2014). Various objectives and subsequently performance indicators can be derived from these criteria in the UWS. Some of these criteria have been traditionally employed for assessment of trade-offs between conflicting criteria such as cost versus reliability representing economic and engineering criteria, respectively. This is due to the fact that conventional urban water management aims to balance water supply-demand with respect to mainly economic criteria (Makropoulos et al., 2008). Relative to these conventional assessment criteria in water systems, assessments including new aspects of the sustainability framework (e.g. greenhouse gas emissions, resilience and social acceptance) may result in lasting benefits for complex socio-ecological systems and ecosystem services (Shah and Gibson, 2013). However, the impact of a holistic performance assessment including both conventional and new sustainability criteria needs to be carefully analysed in the UWS (Lai et al., 2008). Chrysoulakis et al. (2013) has recently employed multi-criteria analysis for assessment of metabolism based performance of a number of urban planning alternatives such as 
changing land use and urban design. They also benefited from other existing models for calculating metabolic fluxes in urban areas and combined them into a structured geo-database (ESRI ArcGIS).

Despite plethora of recent advances in the development of urban water system modelling and metabolism models, to the best of the authors' knowledge, none of the previous works has investigated a metabolism multi-criteria based performance assessment for strategic planning of the integrated UWS including the main components of water supply, wastewater and stormwater subsystems. Hence, the aim of this paper is to explore the detailed impact of integration of the UWS components on the metabolism based performance assessment when a number of optional intervention strategies are applied. This paper also aims to explore the impact of both conventional and sustainability type criteria on this assessment for long-term planning (e.g. 20-40 years) in the UWS. Next section presents the methodology followed by illustrating the case study and the analysed intervention strategies. The results are then discussed along with summarising key findings and recommendations for future works.

\section{Methodology}

A number of potential intervention strategies are employed in this study for assessment of metabolism based performance of the UWS based on two approaches: (1) planning for only water supply system as part of the UWS and (2) planning for an integrated UWS including with potable water, stormwater, wastewater and water recycling. The intervention strategy is defined here as a set of individual intervention options occurring over the defined planning horizon, each with pre-specified timing. Selection of an appropriate modelling approach is the first step for a strategic level assessment of optional interventions. Drawing upon the aforementioned review of the existing approaches, WaterMet $^{2}$ is used here to calculate quantitative performance indicators in the two UWS approaches (Behzadian et al., 2014a). WaterMet ${ }^{2}$ supports simulation of intervention option strategies (Morley et al., 2015). Each intervention strategy is affected by modifying the relevant variables in WaterMet ${ }^{2}$ once reaching a pre-specified timing following the implementation of some intervention(s) and then rerunning the simulation from that point onwards until the end of the planning horizon. The 
performance of potential intervention strategies, quantified over the planning horizon, is then compared with each other and subsequently ranked using a multi-criteria decision analysis (MCDA) method. Further details of the models employed in this paper are described in the following.

\subsection{Integrated UWS model in WaterMet ${ }^{2}$}

WaterMet $^{2}$ is a conceptual, simulation-type, mass-balance-based model which is used here to quantify metabolism related performance of the UWS over a long-term planning horizon (Behzadian et al., 2014b; Behzadian and Kapelan, 2015). The WaterMet ${ }^{2}$ model can simulate any combination of the main UWS components in clean water supply, stormwater collection and wastewater treatment infrastructures as shown in Fig. 1. Any arbitrary number of each type of the UWS components (e.g. conveyance type, storage type and subcatchment) can be defined in WaterMet ${ }^{2}$. The model also adopts a simplified approach for water supply in which 'source to tap' modelling is performed based on six types of the UWS components (Loucks et al., 2005; Rozos and Makropoulos, 2013). More specifically, the water supply infrastructure, as shown in Fig. 1a, is split into three conveyance components (water supply conduits, distribution mains and trunk mains) and three storage components (water resources, WTWs and service reservoirs). The clean water is consumed by customers, which can be supported in WaterMet $^{2}$ by defining various types of water demand profiles shown in Fig. 1b. All this, in turn, enables WaterMet ${ }^{2}$ to simulate water recycling options (i.e., rainwater harvesting and grey water recycling schemes). In particular, rainwater harvesting tank in WaterMet ${ }^{2}$ can potentially provide collected rainwater for all water demand profiles while grey water recycling tank can provide treated grey water only for toilet flushing and irrigation (see Fig. 1b). In WaterMet ${ }^{2}$, grey water recycling tank can collect grey water from consumption of some household appliances and fittings (i.e. hand basin, shower, dish washer and washing machine), industrial \& commercial and frost tapping. Similarly, a simplified approach is adopted for modelling wastewater/stormwater infrastructure. The corresponding key components modelled in this subsystem, shown in Fig. 1a, include combined/separate sewer

network 'routes', WWTWs and receiving water bodies. WaterMet ${ }^{2}$ can also support simulation of 
treatment processes, chemicals consumption, sludge and typical resource recovery options (e.g. biogas, ammonium nitrate and urea) in both WTWs and WWTWs. Thus, water recycling options can be defined in WaterMet ${ }^{2}$ by either decentralised schemes in subcatchments or centralised schemes such as treated wastewater recycling from WWTWs (IWA, 2012).
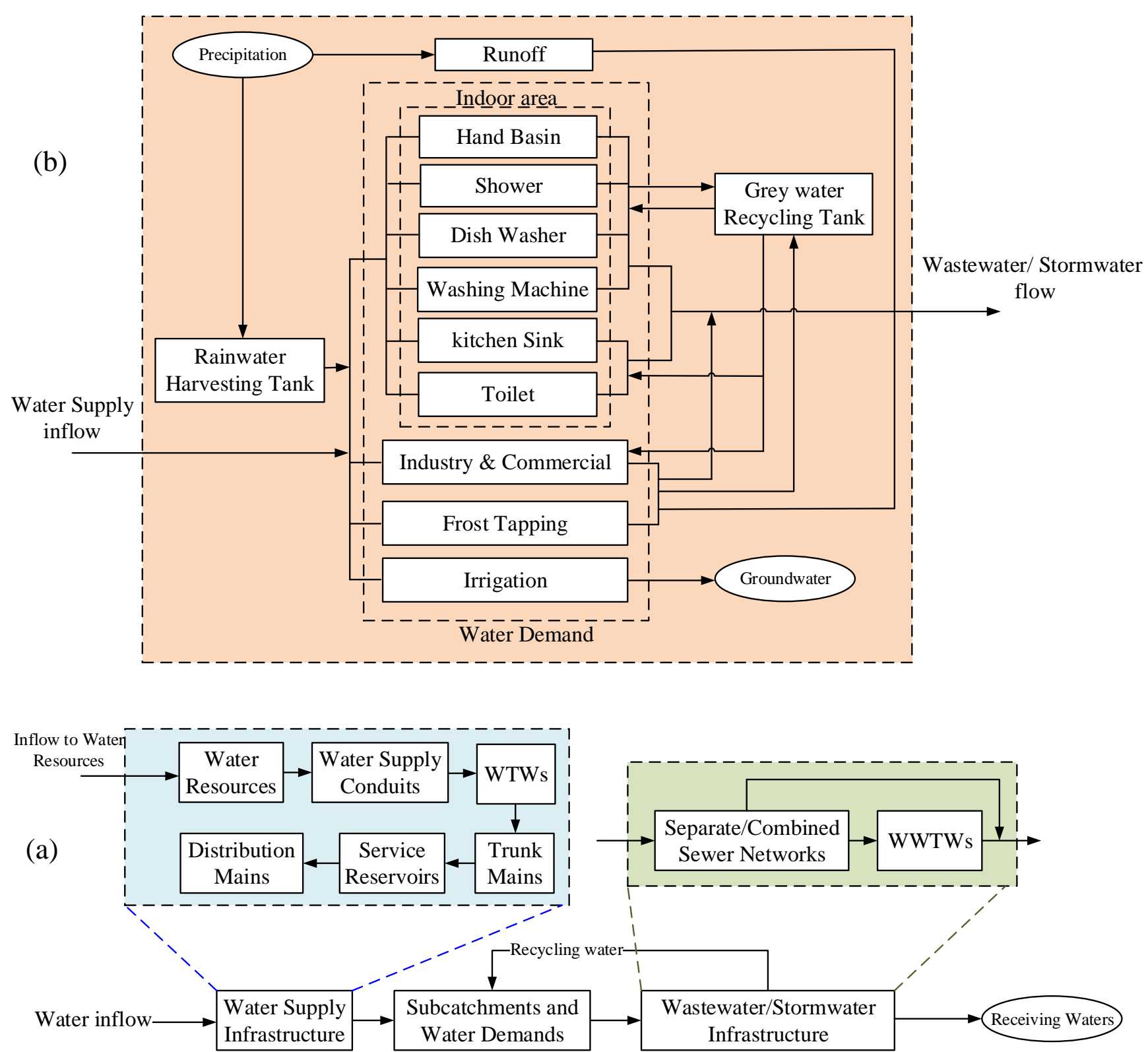

Fig.1. Main UWS elements of WaterMet ${ }^{2}$ including (a) main subsystems and components; (b) details of water demand profiles and water recycling options in subcatchments 
WaterMet ${ }^{2}$ also tracks down a number of metabolism based fluxes within the operating phase of the UWS by using a range of input mass fluxes (e.g. water inflow, precipitation, energy and chemicals used) as shown in Fig. 2. This, in turn, will enable WaterMet ${ }^{2}$ to calculate metabolism related indicators including principal water-related flows and other environmental and financial fluxes. The principal metabolism flows/fluxes quantified by WaterMet ${ }^{2}$ include: (1) water flows (Makropoulos et al., 2008); (2) energy; (3) GHG emissions; (4) acidification potentials; (5) eutrophication potentials; (6) chemicals; (7) pollutants; (8) costs. Due to supporting strategic planning, WaterMet ${ }^{2}$ will use daily time steps as the default and smallest temporal scale to simulate the UWS performance for a period of $N$ years which is specified by the user. A minimum of one year taking into account any seasonal variations of water demands can be envisaged but longer simulation durations typically spreading across multiple years (e.g. 20-40 years) are more desirable to be defined over a long-term planning horizon. Further details of WateMet ${ }^{2}$ modelling processes and assumptions can be found in Behzadian et al. (2014a), Behzadian and Kapelan (2015) and Venkatesh et al. (2015).

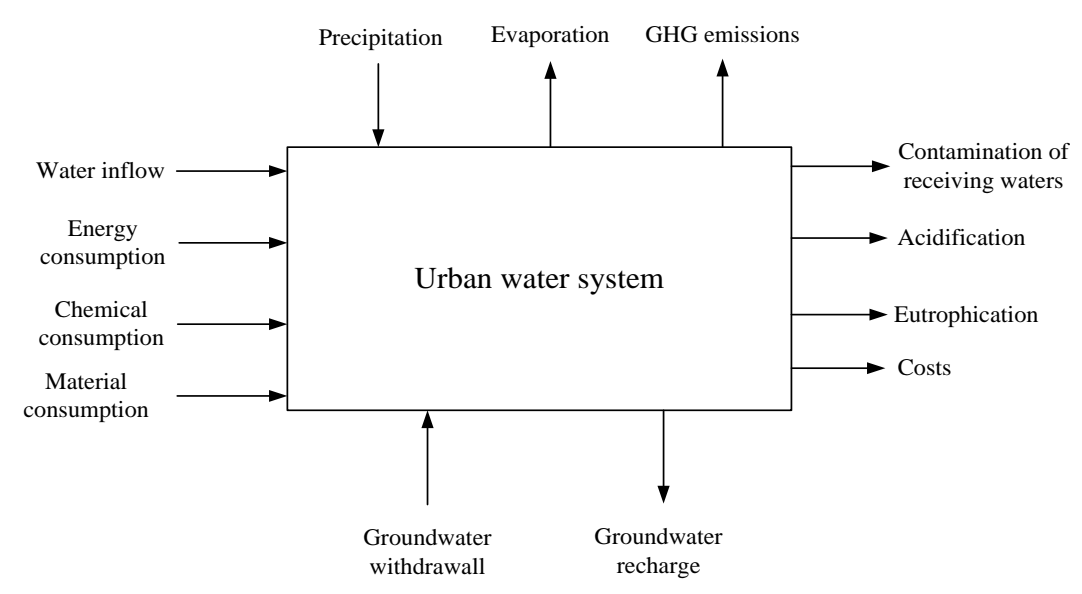

Fig.2. Principle mass fluxes modelled within the UWS metabolism by WaterMet ${ }^{2}$

\subsection{Compromise Programming (CP) method}

Different intervention strategies, simulated by using WaterMet ${ }^{2}$ model, need to be compared and ranked with respect to a number of specified performance criteria. Here, the Compromise Programming 
(CP) method is used as a MCDA technique to compare the calculated key performance indicators for different intervention strategies. The CP method, originally proposed by Zeleny (1973), calculates a distance function for each strategy based on a subset of efficient solutions (called the compromise set) that is "nearest" to an 'ideal' point, for which all criteria are optimized (André and Romero, 2008). The strategies are then ranked according to these distances. Without loss of generality, assuming all criteria are maximising, the overall distance function for an intervention strategy with an evaluation function $\left(f_{i}\right)$, maximum absolute (ideal) value $\left(f_{i}^{*}\right)$, minimum absolute (anti-ideal) value $\left(f_{i *}\right)$, and weight or relative importance $\left(w_{i}\right)$ for criterion $i$ and a topological metric of $p$ is calculated as

$$
\text { minimise } L_{p} \equiv\left[\sum_{i=1}^{n c r i t e r i a}\left(w_{i}\left(f_{i}^{*}-f_{i}\right) /\left(f_{i}^{*}-f_{i *}\right)\right)^{p}\right]^{1 / p}, w_{i}>0,1 \leq p \leq \infty
$$

The magnitude of parameter $p$, ranging between 1 and infinity, indicates the maximum deviation which can be reflective of decision makers' concern (Fattahi and Fayyaz, 2010). The evaluation functions in Eq. (1) are the UWS performance indicators derived from different aspects of sustainability criteria. In other words, each term of Eq. (1) is the impact of one performance indicator, normalised based on its distance from ideal point and the distance between ideal and anti-ideal points, on the overall distance function. In particular, the ideal point for each indicator should be selected carefully based on the real target points of decision makers (Fattahi and Fayyaz, 2010). This is important due to the fact that the difference of performance between various intervention strategies may be negligible for a performance indicator if the selected ideal point of that indicator is far away from all calculated performance indicators.

\subsection{UWS performance indicators}

A plethora of performance indicators can be derived from a specific set of sustainability criteria for assessment of intervention strategies in the UWS (Lai et al., 2008). This complexity will increase with various classifications of sustainability criteria being defined in water systems by different researchers 
such as Ashley et al. (2004), Makropoulos et al. (2008) and Alegre et al. (2012). The key performance indicators (KPIs) used here for comparison of intervention strategies have strived to cover five dimensions of the sustainability framework (i.e. social, environmental, economic, governance and asset) suggested by Alegre et al. (2012). On the basis of this framework, thirteen KPIs, listed in Table 1, were carefully selected under two categories of six conventional KPIs and seven sustainability type KPIs from the literature of sustainability assessments in the UWS (Sahely et al., 2005; Makropoulos et al., 2008; Lai et al., 2008; Shah and Gibson, 2013; Willuweit and O’Sullivan, 2013; Venkatesh et al., 2014). This selection was also made by taking into account the specific issues addressed in the case study analysed. It should also be noted that other KPIs may be added to this list if and where decision makers feel that they are required to address case study specific issues. The conventional KPIs which have been widely evaluated by many models in the UWS are two economic indicators (capital and operations and maintenance (O\&M) costs), one social (reliability), two asset types (leakage and CSO volume) and one environmental (total contaminants). The sustainability type KPIs are the measured metrics derived from the generic concept of the sustainability criteria in the UWS. These KPIs which have received more attention in recent decades focus mainly on reduction in adverse environmental impacts and public concerns (Esty et al., 2008). Hence, three sustainability KPIs, selected from environmental aspects, are (1) GHG emissions as the main sources of Global Warming Potential (GWP100) and climate change presented in IPCC (2006) (2-3) other main environmental impacts on water quality (acidification and eutrophication potentials) which are the most consistently reported indicators (Esty et al., 2008). The three sustainability KPIs covering the social dimension here are (1) vulnerability as a measure for sustainable livelihoods approach, (2) public acceptance as a factor of public awareness and satisfactory and (3) company acceptance as sustainable willingness to support a strategy by experts for planning and implementation (Cannon et al., 2003). Resilience is also considered as a measure of sustainability in respect of asset and infrastructure, which indicates the reserved and redundant capacity provided for any future failure periods (Todini, 2000). 
The first eleven KPIs in Table 1 are quantitative measures which can be calculated by WaterMet ${ }^{2}$ over the full length of the defined planning horizon using daily time steps. Note that some of these KPIs (i.e. KPI1-2, KPI4-6, KPI9, KPI10-11) are directly calculated from the output KPIs in WaterMet ${ }^{2}$ while others (i.e. KPI3, KPI7-8) are calculated from the time series of the basic water flows (supply and demand) in WaterMet ${ }^{2}$ as expressed in the table (Behzadian et al., 2014a). The last two KPIs in the Table (i.e. public and company acceptance) are qualitative criteria which are evaluated based on experts' opinions. To quantify these qualitative KPIs, they are assessed using five linguistic terms (extremely low, low, medium, high and extremely high) by experts to represent different categories of subjective judgments. After collecting linguistic terms of experts, they are converted as rating on a scale of acceptance ranging from 1 (the worst) to 10 (the best) as: 1-2 for 'extremely low', 3-4 for 'low', 5-6 for 'medium', 7-8 for 'high' and 9-10 for 'extremely high' term.

Table 1 List of KPIs used in this study

\begin{tabular}{|c|c|c|c|c|}
\hline No & Name & Units & Description & References \\
\hline KPI1 & $\begin{array}{l}\text { Capital cost of } \\
\text { interventions }\end{array}$ & Million $€$ & $\begin{array}{l}\text { Present value (first year) of total capital costs is calculated } \\
\text { for the initial capital investment of intervention options. }\end{array}$ & $\begin{array}{l}\text { Makropoulos et al., } \\
2008 \text {; } \\
\text { Venkatesh et al., } \\
2014\end{array}$ \\
\hline KPI2 & O\&M cost & $\begin{array}{l}\text { Million } \\
€ / \text { year }\end{array}$ & $\begin{array}{l}\text { Present value (first year) of total Operations and } \\
\text { Maintenance }(O \& M) \text { costs is calculated for any fixed and } \\
\text { variable O\&M costs. }\end{array}$ & $\begin{array}{l}\text { Makropoulos et al., } \\
\text { 2008; Venkatesh et } \\
\text { al., } 2014\end{array}$ \\
\hline KPI3 & $\begin{array}{l}\text { Reliability of } \\
\text { water supply }\end{array}$ & $\%$ & $\begin{array}{l}\text { The ratio of the total water delivered to customers }\left(S_{i}\right) \text { to } \\
\text { the total water demand }\left(D_{i}\right) \text { is calculated over the total } \\
\text { number of time steps: } \sum_{i=1}^{\text {ntimesteps }} S_{i} / \sum_{i=1}^{n \text { timesteps }} D_{i}\end{array}$ & $\begin{array}{l}\text { Sahely et al., 2005; } \\
\text { Loucks et al., 2005; } \\
\text { Makropoulos et al., } \\
2008 ;\end{array}$ \\
\hline KPI4 & Leakage & $\begin{array}{l}\mathrm{MCM} / \\
\text { year }\end{array}$ & $\begin{array}{l}\text { Annual average of leakage volume is calculated in all } \\
\text { conveyance components of water supply assuming leakage } \\
\text { is a fixed percentage of water supply in water supply } \\
\text { conveyance components. }\end{array}$ & $\begin{array}{l}\text { Sahely et al., 2005; } \\
\text { Venkatesh et al., } \\
2014 \text {; }\end{array}$ \\
\hline KPI5 & CSO volume & $\begin{array}{l}10^{3} \\
\mathrm{M}^{3} / \text { year }\end{array}$ & $\begin{array}{l}\text { Annual average of spill volume of CSOs is calculated } \\
\text { when daily flow in sewer network exceeds the capacity of } \\
\text { a CSO structure. }\end{array}$ & $\begin{array}{l}\text { Sahely et al., 2005; } \\
\text { Willuweit and } \\
\text { O’Sullivan, 2013; }\end{array}$ \\
\hline KPI6 & $\begin{array}{l}\text { Total } \\
\text { contaminants }\end{array}$ & $\begin{array}{l}10^{3} \\
\text { Tons/ year }\end{array}$ & $\begin{array}{l}\text { Total mass of contaminants (here total nitrogen, } \\
\text { phosphorous and carbon) discharging from CSOs and } \\
\text { WWTWs (either treated or untreated) into receiving water } \\
\text { bodies is calculated. }\end{array}$ & $\begin{array}{l}\text { Willuweit and } \\
\text { O’Sullivan, 2013; } \\
\text { Venkatesh et al., } \\
\text { 2014; }\end{array}$ \\
\hline KPI7 & Vulnerability & $\begin{array}{l}\text { No of } \\
\text { people }\end{array}$ & The number of affected people for which water is not & Sahely et al., 2005; \\
\hline
\end{tabular}




\begin{tabular}{|c|c|c|c|c|}
\hline No & Name & Units & Description & References \\
\hline & $\begin{array}{l}\text { of water } \\
\text { supply }\end{array}$ & & $\begin{array}{l}\text { supplied over a } 24 \text { hour period is calculated using water } \\
\text { supply }\left(S_{i}\right) \text { and demand }\left(D_{i}\right) \text { and population }\left(\text { pop }_{i}\right) \text { of each } \\
\text { time step over the total number of time steps: } \\
\sum_{i=1}^{\text {ntimesteps }}\left(1-S_{i} / D_{i}\right) \times \text { pop }_{i} \text { if } S_{i-1} / D_{i-1}<1 \text { and } S_{i} / D_{i}<1\end{array}$ & Loucks et al., 2005; \\
\hline KPI8 & $\begin{array}{l}\text { Resilience of } \\
\text { water supply }\end{array}$ & $\begin{array}{l}10^{3} \\
\mathrm{M}^{3} / \text { year }\end{array}$ & $\begin{array}{l}\text { Based on the resilience concept related to redundant } \\
\text { capacity of water supply during pipe failure (Todini 2000), } \\
\text { this indicator is calculated by averaging the redundant } \\
\text { capacity over the number of independent failure states and } \\
\text { time steps: } \\
\sum_{i=1}^{\text {ntimesteps nfailures }} \sum_{j=1}\left(S_{i j}-D_{i}\right) / \text { ntimesteps } \times \text { nfailures } \\
\text { Given the number of failure states in which one of the } \\
\text { water supply components is out of service, redundant } \\
\text { capacity (as either positive value for reserve water or } \\
\text { negative value for water deficit) in a time step is the } \\
\text { difference between water demand }\left(D_{i}\right) \text { and potential } \\
\text { capacity of water supply }\left(S_{i j}\right) \text {. }\end{array}$ & $\begin{array}{l}\text { Todini 2000; } \\
\text { Sahely et al., 2005; } \\
\text { Loucks et al., 2005; }\end{array}$ \\
\hline KPI9 & $\begin{array}{l}\text { GHG } \\
\text { emissions }\end{array}$ & $\begin{array}{l}10^{3} \\
\text { Tons/ year }\end{array}$ & $\begin{array}{l}\text { Annual average of the greenhouse gas emissions (caused } \\
\text { and avoided) is calculated in } \mathrm{kg} \text { of carbon dioxide } \\
\text { equivalents }\left(\mathrm{CO}_{2} \text {-eq) for both gas emitted directly (e.g. }\right. \\
\text { fossil fuel consumption) and indirectly (e.g. embodied } \\
\text { energies consumed for electricity and chemicals). }\end{array}$ & $\begin{array}{l}\text { Change, 2007; } \\
\text { Sahely et al., 2005; }\end{array}$ \\
\hline $\begin{array}{l}\text { KPI1 } \\
0\end{array}$ & Acidification & Tons/ year & $\begin{array}{l}\text { Annual average of acidification potential (caused and } \\
\text { avoided) is calculated in } \mathrm{kg} \text { of } \mathrm{SO}_{2} \text { equivalents from the } \\
\text { major acidifying gas emissions. }\end{array}$ & $\begin{array}{l}\text { Willuweit and } \\
\text { O’Sullivan, 2013; } \\
\text { Venkatesh et al., } \\
\text { 2014; }\end{array}$ \\
\hline $\begin{array}{l}\text { PKI1 } \\
1\end{array}$ & Eutrophication & $\begin{array}{l}10^{3} \\
\text { Tons/ year }\end{array}$ & $\begin{array}{l}\text { Annual average of eutrophication potential (caused and } \\
\text { avoided) is calculated in } \mathrm{kg} \text { of } \mathrm{PO}_{4} \text { equivalents from the } \\
\text { emissions to both atmosphere and water in different forms. }\end{array}$ & $\begin{array}{l}\text { Sahely et al., } 2005 \text {; } \\
\text { Venkatesh et al., } \\
2014 \text {; }\end{array}$ \\
\hline $\begin{array}{l}\text { KPI1 } \\
2\end{array}$ & $\begin{array}{l}\text { Public } \\
\text { acceptance }\end{array}$ & - & $\begin{array}{l}\text { The extent an intervention strategy would be supported by } \\
\text { society, especially consumers, in order to fulfil the water } \\
\text { demands with respect to a number of factors such as water } \\
\text { quality, service quality. }\end{array}$ & $\begin{array}{l}\text { Sahely et al., 2005; } \\
\text { Lai et al., 2008; } \\
\text { Makropoulos et al., } \\
2008 \text {; }\end{array}$ \\
\hline $\begin{array}{l}\text { KPI1 } \\
3\end{array}$ & $\begin{array}{l}\text { Company } \\
\text { acceptance }\end{array}$ & - & $\begin{array}{l}\text { The acceptability and willingness to support a strategy by } \\
\text { water companies, either private or public. }\end{array}$ & $\begin{array}{l}\text { Willuweit and } \\
\text { O’Sullivan, 2013; }\end{array}$ \\
\hline
\end{tabular}

Once the values of all analysed KPIs are obtained using WaterMet ${ }^{2}$ and the qualitative method outlined above, the overall distance of each intervention strategy with respect to multiple criteria is calculated based on Eq. (1) and then the intervention strategies are ranked based on the CP method. Note that the ideal point in the CP method can be either maximum absolute function for maximising a KPI or minimum absolute function for minimising a KPI. The KPIs minimising here are capital cost, 
O\&M cost, leakage, GHG emissions, acidification potential, eutrophication potential, CSO volume, total contaminants and vulnerability. The remaining four KPIs, i.e. reliability, resilience, public acceptance and company acceptance, are maximised.

\section{Case Study}

\subsection{Problem description}

The proposed methodology was demonstrated here for 30-year planning of a real-world UWS of a northern European city. The UWS will face a number challenges among which population growth is likely to impose significant strains on the UWS performance for future planning. As a result, it is predicted that the city population with $\sim 750,000$ inhabitants in 2014 is estimated to reach approximately 1,240,000 inhabitants in 2045 based on the highest foreseen rate of population growth. A brief description of the case study are outlined here.

Fig. 3 shows a schematic representation of the analysed UWS which comprises two distinctive water supply routes (indicated as 1 and 2 with solid-line components in the figure), each including one Water Resource (WR), Water Supply Conduit (WSC), Water Treatment Works (WTW), Trunk main (TM), Service Reservoir (SR) and Distribution Main (DM). Out of the total fresh water supply, route 1 and 2 provides approximately $90 \%$ and $10 \%$ of total supply capacity, respectively. As such, the two existing water resources are of limited capacity (120 and 13.8 million cubic metres (MCM)) and inflow (average of 287 and $12 \mathrm{MCM} / \mathrm{year}$ ). The single defined subcatchment accommodates various types of water demands including domestic, commercial, garden watering, frost tapping and unregistered public use in the UWS. The domestic (indoor) water demand per capita is further split into the six types of appliances and fittings outlined previously. The current leakage from the pipelines is estimated to be approximately $22 \%$ of total water demand. There is also a single sewer network connected to two WWTWs collecting 63\% (WWTW1) and 37\% (WWTW2) of the stormwater and sanitary sewage flow. Any treated 
wastewater from WWTWs and untreated wastewater/stormwater exceeding the sewerage capacities are discharged into the only receiving water body (RW1) at the most downstream point of the UWS.

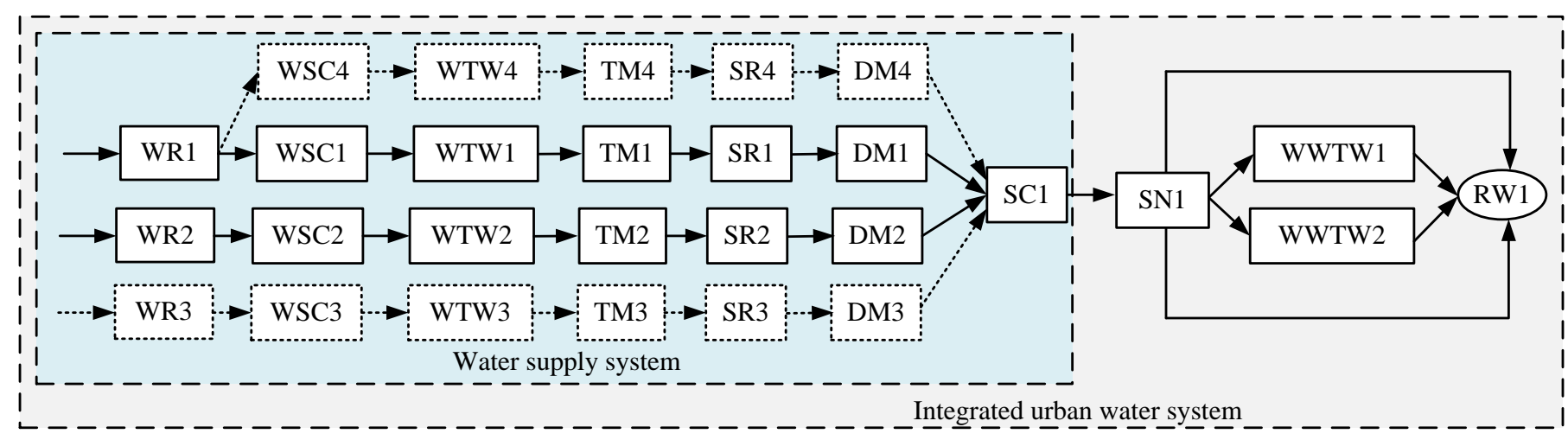

Fig.3. Schematic representation of the main UWS components modelled in WaterMet ${ }^{2}$; The dashed components show the new components related to the intervention strategy of "new water resource"; Also note that WR=water resource, WSC=water supply conduit, WTW=water treatment works, TM=trunk main, SR=service reservoir, DM=distribution main, $\mathrm{SC}=$ subcatchment, $\mathrm{SN}=$ sewer network, WWTW=wastewater treatment works and $\mathrm{RW}=$ receiving water body

Given the input data outlined here and the information provided by the relevant water company, the WaterMet ${ }^{2}$ model was built. The historic time series of rainfall and inflows to the water resources over the past 30 years were used for this analysis assuming the same trend will happen over the planning horizon. The model calibration in the current version of WaterMet ${ }^{2}$ can be done using a manual, trial and error approach and hence it was pursued here although the model calibration accuracy can be improved by automated (e.g. optimised) calibration. As a result, the model was calibrated and validated for both water supply and stormwater/wastewater subsystems sequentially using the historical daily measurements available. In water supply subsystem, two years of recorded and available daily water production at the WTWs were split into two periods of 2011 for calibration and 2012 for validation. The stormwater/ wastewater subsystem was subsequently calibrated and validated for two years of 2010 and 2011 of recorded daily wastewater inflows to the WWTWs, respectively. The simulated values in both subsystems were reasonably close to the observed values (not shown here) although the accuracy of the calibration in the wastewater part is better than the water supply part. This can be attributed to the fact that daily water demands are highly variable over a year, not necessarily corresponding with temperature and calendar monthly variations defined by the WaterMet ${ }^{2}$ model but other impacts such as 
human behaviours (e.g. tourism and holidays). Further details of the calibration procedure in the WaterMet ${ }^{2}$ model can be found in Behzadian and Kapelan (2015).

\subsection{Intervention strategies}

In order to tackle the increased water demand due to high population growth in the future, a number of intervention strategies were investigated for the future planning. Hence, the following five individual intervention options which can be simulated by WaterMet ${ }^{2}$ were employed here for developing intervention strategies:

(1) New water resource: This option considers (a) adding a new water resource (with a large capacity of 13,000 MCM) where no infrastructure exists for conveyance of raw water and (b) expansion of an existing water resource. As a result, this option will add the new water resource (WR3) and subsequent new water supply route 3 (i.e. WR3, WSC3, WTW3, DM3, SR3 and DM3) and expand the existing water resource (WR1) by adding the new route 4 (i.e. WSC4, WTW4, DM4, SR4 and DM4), which are shown in Fig. 3 as dashed-line components. (2) Increase in pipeline rehabilitation: A rehabilitation strategy based on the 'oldest-first' principle is adopted here, in which, when additional annual rehabilitation is applied, leakage decrease is proportional to the length and age of the rehabilitated pipes (Behzadian et al., 2014b). At the current rate of pipeline rehabilitation (1\%), three possible rates of increase in annual rehabilitation $(0.2 \%, 0.5 \%$ and $1.0 \%$ of the total length per year) are analysed as intervention options. (3) Water meter installation in households: Given water meter installation would result in an estimated reduction of $10 \%$ in water demand (Butler and Davies, 2004), the installation of a fixed number of water meters for household users, per year, can be looked upon as an effective intervention option. As no water meters are installed in households of the city in the first year of analysis, two annual rates of water meter installation are investigated here, being $5 \%$ and $10 \%$ of the total households. (4) Rainwater Harvesting (RWH) scheme: A single RWH scheme (Ward et al., 2012; Behzadian et al., 2014c) representing many small domestic RWH units across the city is assumed in the subcatchment. Two rates of adoption of the RWH scheme (25\% and $50 \%$ of households) are analysed 
as intervention options. The RWH scheme collects runoff from roofs, roads and pavements and supplies water for toilet flushing, garden watering and industrial usages. (5) Grey Water Recycling (GWR) scheme: Similarly, a representative GWR scheme (Memon et al., 2005; Behzadian et al., 2014c) across the city are considered with two rates of $25 \%$ and $50 \%$ of adoption in households. The GWR scheme collects grey water (i.e. from the hand basin, dish washer, shower, washing machine and frost tapping) and recycles the treated grey water for the provision of toilet flushing, irrigation and industrial uses.

Based on combining the aforementioned intervention options, Table 2 lists the eleven intervention strategies derived from these options, each occurring at a specific point in time, to illustrate a number of potential strategies for improving the UWS performance over the planning horizon. Strategy 1 'business as usual (BAU)' is effectively 'do nothing' in the UWS, leaving the water resource situation and the pipe rehabilitation rates unchanged. To create the intervention strategies, up to four intervention options have been combined with different levels of implementation.

Table 2 Intervention strategies analysed in this study

\begin{tabular}{|c|c|c|c|c|}
\hline \multirow{2}{*}{$\begin{array}{l}\text { Strategy } \\
\text { ID }\end{array}$} & \multicolumn{3}{|c|}{ Description of intervention options } & \multirow{2}{*}{$\begin{array}{l}\text { Start } \\
\text { year }\end{array}$} \\
\hline & Rehabilitation & $\begin{array}{l}\text { Supply } \\
\text { augmentation }\end{array}$ & Metering & \\
\hline S1 (BAU) & - & - & - & - \\
\hline S2 & - & new water resource & - & 2025 \\
\hline S3 & $\begin{array}{l}1 \% \text { additional } \\
\text { rehabilitation annually }\end{array}$ & - & - & 2020 \\
\hline S4 & $\begin{array}{l}0.5 \% \text { additional } \\
\text { rehabilitation annually }\end{array}$ & - & $\begin{array}{l}5 \% \text { additional water } \\
\text { meter annually }\end{array}$ & 2020 \\
\hline S5 & $\begin{array}{l}0.2 \% \text { additional } \\
\text { rehabilitation annually }\end{array}$ & - & $\begin{array}{l}10 \% \text { additional water } \\
\text { meter annually }\end{array}$ & 2020 \\
\hline S6 & - & $25 \%$ RWH scheme & $\begin{array}{l}10 \% \text { additional water } \\
\text { meter annually }\end{array}$ & 2020 \\
\hline S7 & - & $25 \%$ GWR scheme & $\begin{array}{l}10 \% \text { additional water } \\
\text { meter annually }\end{array}$ & 2020 \\
\hline S8 & - & $\begin{array}{l}25 \% \text { RWH \& } 25 \% \\
\text { GWR schemes }\end{array}$ & - & 2020 \\
\hline S9 & - & $\begin{array}{l}50 \% \text { RWH \& } 50 \% \\
\text { GWR schemes }\end{array}$ & - & 2020 \\
\hline S10 & $\begin{array}{l}0.5 \% \text { additional } \\
\text { rehabilitation annually }\end{array}$ & $\begin{array}{l}50 \% \text { RWH \& } 50 \% \\
\text { GWR schemes }\end{array}$ & $\begin{array}{l}10 \% \text { additional water } \\
\text { meter annually }\end{array}$ & 2020 \\
\hline S11 & $\begin{array}{l}0.2 \% \text { additional } \\
\text { rehabilitation annually }\end{array}$ & $\begin{array}{l}25 \% \text { RWH \& } 25 \% \\
\text { GWR schemes }\end{array}$ & $\begin{array}{l}5 \% \text { additional water } \\
\text { meter annually }\end{array}$ & 2020 \\
\hline
\end{tabular}




\section{Results and discussion}

Intervention strategies were analysed here for two cases: (I) strategic planning for Water Supply System (WSS) rehabilitation/upgrade only as a part of the UWS shown in Fig. 3 and (II) strategic planning for rehabilitation/upgrade of integrated UWS shown in Figs. 1 and 3. In addition, the intervention strategies in each case were evaluated and ranked for two sets of criteria: (1) conventional indicators only and (2) both conventional and sustainability type indicators. In all cases, WaterMet ${ }^{2}$ evaluated the eleven aforementioned intervention strategies in the system for a period of 30 years starting from 2015 with daily time steps. All rankings obtained by the CP method in Eq. (1) assume equal weights for the analysed criteria and topological metric $(p)$ equal to 2 . In addition, the minimum and maximum absolute values in Eq. (1) are the extreme KPI values of the intervention strategies for each criterion.

\subsection{Case I: water supply system rehabilitation/upgrade only}

The intervention strategies were first evaluated for the analysis of the WSS alone using the nine criteria/KPIs including four conventional (capital cost, O\&M cost, reliability and leakage) and five sustainability type (GHG emissions, resilience, vulnerability, public acceptance and company acceptance). GHG emissions, acidification and eutrophication potentials in the WSS analysis are all obtained from electricity and fossil fuel consumptions only. Thus, GHG emissions were only considered in this case as the other two environmental impacts are simply a factor of this KPI. The two remaining KPIs (i.e. CSO volume and total contaminants) were excluded as they are only related to wastewater/stormwater subsystem.

The KPIs assessment for the eleven intervention strategies applied to the WSS is presented in Table 3. It is evident that the suggested intervention strategies would result in noticeable improvements compared to the BAU case (S1) though some deterioration in criteria values are observed in some cases (e.g. GHG emissions and leakage in S2 or public acceptance in S5-11). In particular, water supply 
reliability usually as the first priority of many water authorities improves in new intervention strategies particularly Strategy 2 with the highest reliability value. In the case of strategies targeted at demand management (S3-11), leakage reduction occurs owing to an increase in the annual rehabilitation rate (direct impact) or the introduction of water metering, GWR and RWH schemes (indirect impact). The highest reduction in annual average leakage is achieved by Strategy 10 which benefits from a high rate of both direct and indirect impacts.

On the other hand, the highest leakage is seen to occur under the 'new water resource' strategy (S2) due to the provision of additional water to meet future demands without any commensurate demand management measures which would positively affect leakage. The fewest number of people affected by interruption over 24 hours (vulnerability) occur in Strategies 2 and 10. The magnitude of difference between these two strategies (particularly strategy \#2) and the remainder is substantial for this indicator. This can be linked to the largest capital investment made in these strategies relative to others. Moreover, results also reveal that only strategy 2 can cause a positive value of resilience indicator (i.e. actual redundant capacity) owing to the capacity obtained from a new water resource.

Table 3 Performance indicators of intervention strategies and their ranks in the WSS

\begin{tabular}{|c|c|c|c|c|c|c|c|c|c|c|c|}
\hline \multirow{3}{*}{$\begin{array}{l}\text { Strategy } \\
\text { number }\end{array}$} & \multicolumn{4}{|c|}{ Conventional criteria } & \multicolumn{5}{|c|}{ Sustainability criteria } & \multirow{3}{*}{$\begin{array}{l}\text { Rank based } \\
\text { on } \\
\text { Conventional } \\
\text { criteria only }\end{array}$} & \multirow{3}{*}{$\begin{array}{c}\text { Rank based } \\
\text { on all } \\
\text { criteria }\end{array}$} \\
\hline & $\begin{array}{c}\text { Capital } \\
\text { cost }\end{array}$ & $\mathrm{O} \& \mathrm{M}$ cost & Reliability & Leakage & Vulnerability & Resilience & $\begin{array}{c}\text { GHG } \\
\text { Emissions }\end{array}$ & $\begin{array}{c}\text { Public } \\
\text { acceptance }\end{array}$ & $\begin{array}{l}\text { Company } \\
\text { acceptance }\end{array}$ & & \\
\hline & Million $€$ & $\begin{array}{l}\text { Million } \\
€ / \text { year }\end{array}$ & $\%$ & $\begin{array}{c}\text { MCM/ } \\
\text { year }\end{array}$ & No of people & $\begin{array}{c}10^{3} \mathrm{M}^{3} / \\
\text { year }\end{array}$ & $\begin{array}{c}10^{3} \text { Tons/ } \\
\text { year }\end{array}$ & - & - & & \\
\hline S1 & 0 & 25 & 94 & 28 & 56 & -162 & 37 & 5 & 3 & 5 & 10 \\
\hline $\mathbf{S 2}$ & 399 & 32 & 100 & 30 & 2 & 454 & 41 & 9 & 10 & 11 & 2 \\
\hline S3 & 135 & 25 & 96 & 22 & 36 & -146 & 37 & 7 & 6 & 1 & 1 \\
\hline S4 & 127 & 25 & 96 & 25 & 37 & -146 & 36 & 5 & 4 & 2 & 3 \\
\hline S5 & 96 & 25 & 96 & 26 & 37 & -145 & 36 & 4 & 3 & 3 & 6 \\
\hline S6 & 185 & 28 & 97 & 24 & 21 & -106 & 33 & 3 & 2 & 7 & 5 \\
\hline S7 & 98 & 25 & 97 & 26 & 25 & -129 & 37 & 2 & 2 & 4 & 8 \\
\hline S8 & 139 & 29 & 97 & 24 & 20 & -102 & 35 & 2 & 2 & 6 & 7 \\
\hline S9 & 278 & 33 & 98 & 23 & 11 & -80 & 35 & 1 & 2 & 9 & 11 \\
\hline S10 & 414 & 33 & 99 & 19 & 5 & -60 & 34 & 1 & 4 & 10 & 9 \\
\hline S11 & 226 & 29 & 98 & 23 & 13 & -92 & 34 & 2 & 3 & 8 & 4 \\
\hline
\end{tabular}

In this case study, it was assumed that the 'public acceptance' criterion is mainly affected by the three factors of water quality, availability and water pressure while the 'company acceptance' criterion 
reflects the attitude of water companies with respect to the available facilities, capabilities and costs. For instance, the BAU strategy (S1) has little support from either public or Water Company because of relatively inappropriate performance of this strategy with respect to the criteria related water supply (e.g. reliability, vulnerability, resilience) and thus they are ranked low. By contrast, the 'new water resource' strategy is ranked the highest for both the public and water companies. The next most highlyregarded strategies for the public and water companies are those containing rehabilitation, as in these cases, both the incidence of breaks and the quantity of leakage is likely to be reduced. The strategies containing RWH and GWR schemes receive the least support from both the public and water companies owing to general concerns mainly relating to water quality and health issues.

The intervention strategies were then ranked using the CP method based on two sets of criteria as shown in the two right-hand columns of Table 3. The first ranking is based on only four conventional criteria of the WSS. The second ranking employs all nine criteria including both conventional and sustainability type. The best ranked strategy (S3) in both rankings is the best with respect to only one criterion (i.e. O\&M) while it is ranked average in respect of other criteria. On the other hand, Strategy 2 even with the highest reliability is ranked the lowest in the first ranking because its position has been among the worst ranked strategies in other conventional criteria. However, this strategy is ranked number 2 in the second ranking in favour of the highest positive impact in respect of four out of five sustainability type criteria. Furthermore, the strategies containing interventions in rehabilitation are generally ranked high in the WSS while those strategies promoting 'water demand' management (e.g. SS6-S11 with RWH and GWR schemes) obtain lower ranks. Interestingly, based on the result in the first ranking, the BAU (S1) is prioritised over many 'water demand' management strategies. This is because these strategies show no meaningful priority over other strategies with respect to many criteria related to the WSS although they have been amongst the top ones in respect of few criteria. This suggests that, in this instance, the strategies containing 'water supply' type interventions (i.e. new water 
resource) generally outperforms the 'water demand' type strategies (e.g. those containing RWH and GWR schemes) when the analysis is focused on water supply systems and the relevant criteria.

\subsection{Case II: integrated urban water system rehabilitation/upgrade}

The wastewater subsystem was added to the assessment approach in the second case to create the integrated UWS. Thus, the existing sewer network, two WWTWs and single receiving water body shown in Fig. 3 were added to the assessment. The same eleven intervention strategies were reevaluated for the integrated UWS against all thirteen assessment criteria given in Table 1 . The newly added criteria compared to those evaluated for the WSS include four quantitative criteria comprising two related to the entire UWS performance (i.e. acidification and eutrophication) and the other two related wastewater subsystem (i.e. total contaminants and CSO volume). Apart from energy consumptions (here electricity and fossil fuel) contributing to environmental impact categories (i.e. GHG emissions, acidification and eutrophication potentials), other caused and avoided emissions to air and discharge to water resulted from wastewater subsystem (mainly from WWTWs) are included in the integrated UWS.

Table 4 presents the performance of the intervention strategies in respect of 13 KPIs in the integrated UWS. Similarly, two rankings of the intervention strategies based on the same two sets of criteria is presented in two right-hand columns of Table 4. It is readily apparent from the results that the superiority of those strategies employing both RWH and GWR schemes (S6-S11) with respect to recently added criteria and subsequently both rankings of the strategies. This can be attributed to the fact that these schemes reduce both runoff entering the sewer network and potable water demand. It is evident that adding sustainability type criteria for evaluating the strategies would rigorously adjust ranking without significant changes being observed. This can be attributed to the fact that the impact of the four newly added sustainability type criteria are somewhat embedded in other conventional criteria of the integrated UWS (i.e. the two types of the criteria are not entirely independent from). This suggests that, in this instance, an approximate ranking can be conducted based on only conventional 
criteria in the case of the integrated UWS but a more accurate ranking of strategies can be obtained once sustainability type criteria are included in the assessment criteria. 
Table 4 Performance indicators of intervention strategies and their ranks in the integrated UWS

\begin{tabular}{|c|c|c|c|c|c|c|c|c|c|c|c|c|c|c|c|}
\hline \multirow{3}{*}{$\begin{array}{l}\text { Strategy } \\
\text { number }\end{array}$} & \multicolumn{6}{|c|}{ Conventional criteria } & \multicolumn{7}{|c|}{ Sustainability criteria } & \multirow{3}{*}{$\begin{array}{c}\text { Ranking } \\
\text { based on } \\
\text { conventional } \\
\text { criteria only }\end{array}$} & \multirow{3}{*}{$\begin{array}{r}\text { Ranking } \\
\text { based on } \\
\text { all criteria }\end{array}$} \\
\hline & $\begin{array}{c}\text { Capital } \\
\text { cost }\end{array}$ & $\begin{array}{c}\mathrm{O} \& \mathrm{M} \\
\text { cost }\end{array}$ & Reliability & Leakage & $\begin{array}{c}\text { CSO } \\
\text { volume }\end{array}$ & $\begin{array}{c}\text { Total } \\
\text { contaminants }\end{array}$ & vulnerability & Resilience & $\begin{array}{c}\text { GHG } \\
\text { emissions }\end{array}$ & Acidification & Eutrophication & $\begin{array}{c}\text { Public } \\
\text { acceptance }\end{array}$ & $\begin{array}{l}\text { Company } \\
\text { acceptance }\end{array}$ & & \\
\hline & $\begin{array}{c}\text { Million } \\
€\end{array}$ & $\begin{array}{c}\text { Million } \\
€ / \text { year }\end{array}$ & $\%$ & $\begin{array}{c}\mathrm{MCM} / \\
\text { year }\end{array}$ & $\begin{array}{c}10^{3} \\
\mathrm{M}^{3} / \text { year }\end{array}$ & $\begin{array}{c}10^{3} \text { Tons } / \\
\text { year }\end{array}$ & $\begin{array}{l}\text { No of } \\
\text { people }\end{array}$ & $\begin{array}{c}10^{3} \mathrm{M}^{3} / \\
\text { year }\end{array}$ & $\begin{array}{c}10^{3} \text { Tons/ } \\
\text { year }\end{array}$ & Tons/ year & $10^{3}$ Tons/ year & - & - & & \\
\hline S1 & 0 & 56 & 94 & 28 & 346 & 13 & 56 & -162 & 167 & 934 & 18 & 5 & 3 & 10 & 11 \\
\hline S2 & 399 & 60 & 100 & 30 & 346 & 13 & 2 & 454 & 171 & 944 & 18 & 9 & 10 & 11 & 7 \\
\hline S3 & 135 & 51 & 96 & 22 & 346 & 13 & 36 & -146 & 167 & 940 & 18 & 7 & 6 & 9 & 6 \\
\hline S4 & 127 & 50 & 96 & 25 & 339 & 12 & 37 & -147 & 164 & 927 & 17 & 5 & 4 & 8 & 9 \\
\hline S5 & 96 & 50 & 96 & 26 & 335 & 12 & 37 & -146 & 161 & 917 & 17 & 4 & 3 & 7 & 10 \\
\hline S6 & 185 & 52 & 97 & 24 & 259 & 10 & 21 & -106 & 155 & 871 & 15 & 3 & 2 & 2 & 1 \\
\hline S7 & 98 & 56 & 97 & 26 & 313 & 11 & 25 & -129 & 156 & 884 & 16 & 2 & 2 & 5 & 8 \\
\hline S8 & 139 & 50 & 97 & 24 & 260 & 10 & 20 & -103 & 158 & 866 & 15 & 2 & 2 & 1 & 4 \\
\hline S9 & 278 & 59 & 98 & 23 & 233 & 10 & 11 & -80 & 155 & 844 & 14 & 1 & 2 & 4 & 5 \\
\hline S10 & 414 & 58 & 99 & 19 & 228 & 9 & 5 & -60 & 149 & 831 & 14 & 1 & 4 & 6 & 2 \\
\hline S11 & 226 & 59 & 98 & 23 & 256 & 10 & 13 & -92 & 155 & 860 & 15 & 2 & 3 & 3 & 3 \\
\hline
\end{tabular}


Comparison of GHG emissions which are affected by all components in both cases shows that they would increase approximately four times from the WSS to the integrated UWS. This is mainly due to large amount of GHG emissions resulted from the treatment processes in the WWTWs (Metcalf and Eddy, 2003). In this study, GHG emissions in WWTWs are caused from energy consumption, methanol and ethanol usage, incomplete biogas combustion in the treatment processes. Therefore, to alleviate the level of GHG emissions, the primary focus should be essentially on WWTWs as recommended by previous researchers (Mouri and Oki, 2010). This aim is indirectly addressed in this study by reducing the wastewater/stormwater inflow to WWTWs using intervention options relating to water demand management for customers. In addition, the minimum GHG emissions are incurred by Strategies 6 and 10 in both cases, indicating two efficient but different compositions of intervention options which result in the lowest emissions. The improvement of GHG emissions in these 'water-saving' strategies can be attributed to the drop in production of potable water and consequently reduction in energy requirements for bulk transport, treatment and distribution.

Comparison of the variations in all four rankings of the two cases demonstrates that a more holistic perspective assessment by considering an integrated UWS and sustainability type criteria can better assist in selecting the most appropriate intervention strategies. For instance, when considering only conventional criteria, solely the WSS, the top three strategies are Strategies 3, 2 and 4, respectively, whereas these are replaced by completely different strategies (i.e. S6, S10 and S11, respectively) in the integrated UWS ranking. On the other hand, the high ranked strategies in one case are ranked low in the other case. This, of course, is due to the newly-added criteria in the second case. Strategy 2 is the best strategy with respect to five criteria in both cases while its rank declined from $2^{\text {nd }}$ to $7^{\text {th }}$ in the second case. The principal reasons for such a significant demotion in the second case is owing to its rank as the worst in six criteria, including twice for leakage and GHG emissions and for all four wastewater-related criteria. The best strategy in the integrated UWS modelling (i.e. S6), hold neither the best nor the worst 
rank with respect to any of the criteria separately, instead possessing reasonably good values with respect to all criteria, i.e. representing a good compromise solution resulting in a high ranking.

\subsection{Temporal analysis of top intervention strategies}

The assessment of the strategies is further investigated by analysing the annual variations of some KPIs for the top three strategies in case I (i.e. S2, S3, S4) and II (i.e. S6, S10, S11) in Fig. 4 and 5. This has been done in order to discover the main reasons that cause these intervention strategies to be selected as top strategies in each case. Introduction of some 'water-demand' management intervention options (e.g. RWH or GWR schemes) in the top strategies of case II would result in a better performance of per capita value for four indicators shown in Fig 4 for the integrated UWS. However, this trend for the top strategies of case I is almost unchanged compared to the BAU state. The variations of annual per capita amount for GHG emissions (Fig. 4c) and acidification (Fig. 4a) follow a decreasing trend due to high population growth. However, this trend for eutrophication (Fig. 4b) and total contaminants (Fig. 4d) is almost steady although they have fluctuations over the planning horizon. This can be linked to the fact that a high proportion of these indicators are resulted from CSO volume which are strongly driven by precipitation time series (climate input) rather than population growth. In particular, two peaks are observed for these two KPIs for all strategies in 2022 and 2034 due to a high rate of annual stormwater in these two years (i.e. 120 and $140 \mathrm{MCM}$, respectively), when the average annual stormwater over the planning horizon is $94 \mathrm{MCM}$. Given the uncertainty of the future climate, this indicates that the UWS should expect such these shocks for these two KPIs for almost all intervention strategies once the events of rainfall-induced runoff exceed the capacity of urban drainage systems. 

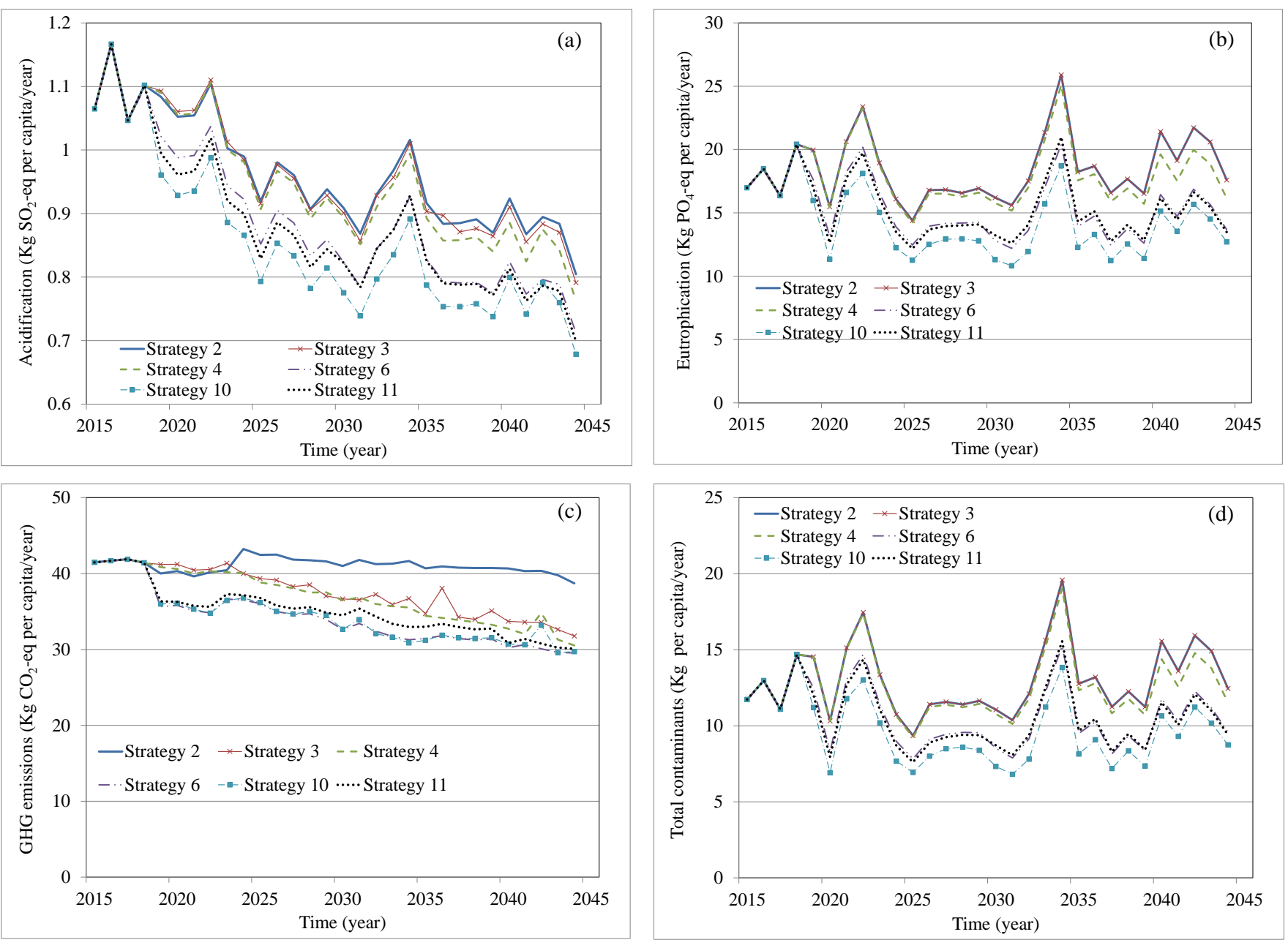

Strategy2: New resource, Strategy3: 1\%rehabilitation, Strategy4: 0.5\%rehabilitation\&5\%meter, Strategy6: 25\% RWH\&10\%meter, Strategy 10: 0.5\%rehabilitation\&50\% RWH\&50\% GWR\&10\%meter, Strategy11: 0.2\%rehabilitation\&25\% RWH\&25\% GWR\&5\% meter

Fig.4. Annual variations for per capita values of KPIs for the top strategies in cases I (i.e. S2, S3, S4) and II (i.e. S6, S10, S11) for (a) acidification, (b) eutrophication, (c) GHG emissions and (d) total contaminants.

Strategy 2 as shown in Fig. 5 provides the best annual performance with respect to three water supply related indicators (reliability, resilience and vulnerability) while it would increase annual leakage by 40\%. All this is due to providing additional potable water in the water supply system. The privilege of this strategy is particularly considerable in resilience in favour of new capacity for water resource and treatment whilst this indicator for other strategies would have a relatively slight improvement and still negative redundant capacity as shown in Fig. 5(d). For those three performances in which Strategy 2 is the best, Strategy 10 is in the second position but the best with respect to annual leakage. The lowest rates of reliability belong to Strategies 3 and 4 because of minimal impact of these strategies on water deficit over the planning horizon. Similarly, this impact in these strategies would result in deteriorating 
of water supply vulnerability to a high annual rate as much as 100,000 people per day during the finishing years of the planning horizon. On the other hand, Strategy 10 can considerably mitigate the affected people to less than 20,000 people per day during those years whilst Strategy 2 can completely resolve the UWS vulnerability over the planning horizon.
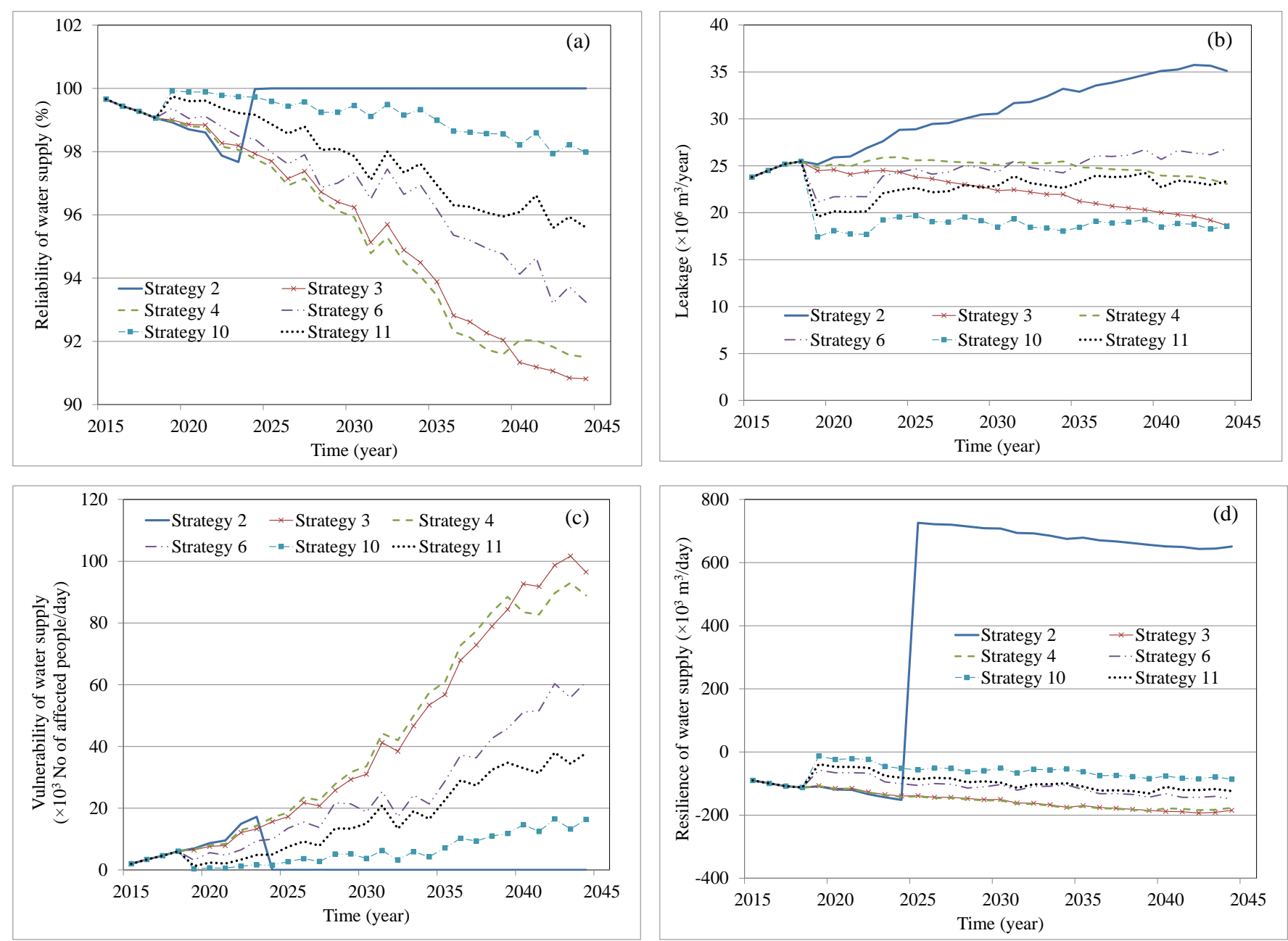

Strategy2: New resource, Strategy3: 1\%rehabilitation, Strategy4: 0.5\%rehabilitation\&5\%meter, Strategy6: 25\% RWH\&10\%meter,

Strategy10: 0.5\%rehabilitation\&50\% RWH\&50\% GWR\&10\%meter, Strategy11: 0.2\%rehabilitation\&25\% RWH\&25\% GWR\&5\%meter

Fig.5. Annual variations of KPIs for the top three strategies in cases I (i.e. S2, S3, S4) and II (i.e. S6, S10, S11) for (a) reliability, (b) leakage, (c) vulnerability and (d) resilience.

\subsection{Further discussions}

The ranking of the strategies is highly dependent on some important factors which should be carefully addressed. Firstly, the assessment criteria and their values should not only be mutually 
inclusive but also avoid being "double counting" relative to all evaluating strategies otherwise the assessment could be skewed towards those strategies which have more supporting criteria (Lai et al., 2008). Secondly, the relative importance (weight) of criteria (i.e. $w_{i}$ in Eq. 1), which may be a key factor for some stakeholders, can have a significant impact on the ranking of strategies (Morley et al., 2014). For instance, the environmental criteria such as reduction of GHG emissions and total contaminants may be of higher priority to a stakeholder such as the Environment Agency whilst criteria such as reliability of supply might be of higher priority to a water utility. In these cases, higher weight should be allocated to high priority criteria or they are set as constraints to remove the strategies not satisfying the thresholds of interest. Finally, the final ranking in the CP method can be somewhat sensitive to extreme values of ideal and anti-ideal points of the individual criteria, which may need further attention from decision makers (Fattahi and Fayyaz, 2010). Therefore, all these factors may affect the KPI values and consequently change the overall ranking.

Furthermore, the above methodology shows that potential intervention strategies should be analysed for an integrated urban water system and then ranked with respect to numerous quantitative and qualitative KPIs covering full dimensions of the UWS sustainability. However, a conclusive ranking of intervention strategies may require an uncertainty analysis owing to imprecision of the input data collected for different parts of the analysis such as infrastructure, external scenarios (e.g. climate change and population growth) and intervention strategies. The aim of uncertainty analysis for UWS parameters is to include the effect of a broader range of nominal parameters values on the model performance (i.e. KPI values), thereby obtaining the robustness of the resulting ranks. In these cases, the relevant parameters with the highest uncertainty need to be incorporated into all this evaluation in an appropriate fashion such as local (regional) and global uncertainty analysis (Saltelli et al., 2006; Fu et al., 2009). For instance, the global analysis approach which considers the interaction between the parameters simultaneously can be used efficiently for this purpose such that the uncertainty is reflected in model KPI values (Fu et al., 2009). 


\section{Conclusions}

A multi-criteria assessment of strategic planning was analysed here to explore the importance of integrated and sustainability type assessment for evaluation of intervention strategies in the UWS. WaterMet ${ }^{2}$ model was used to quantify the metabolism-based performance of the UWS. As a result, eleven intervention strategies were evaluated for simulating two cases: (1) part of the UWS (i.e. the WSS only) and (2) the integrated UWS. The strategies were then ranked for both conventional and sustainability type criteria by using the $\mathrm{CP}$ method. Based on the results obtained, the following can be concluded:

1. Assessment of the full urban water cycle in an integrated fashion is important in the context of long-term (here 30 years) UWS planning as the resulting best intervention strategy(ies) can be quite different when compared to the corresponding best intervention strategies identified by considering only part of the urban water cycle.

2. Sustainability type criteria is undoubtedly important and should be included in the evaluation of metabolism based UWS performance in the context of long-term planning of these systems. In case of the integrated UWS, the results show that a reasonable approximation for the performance assessment can be conducted based on only conventional criteria.

3. The water demand management-based intervention strategies (i.e. that make use of GWR and/or RWH schemes) seem to outperform other strategies when evaluating the integrated UWS performance because of impact on all subsystems (i.e. reduction of runoff and sanitary sewage entering sewer networks and potable water demand in water supply subsystem).

The analyses and subsequent rankings conducted here is for illustrative purposes only, i.e. with the aim of demonstrating the suggested methodology. Although the results express some potential and promising strategies, further analyses including multiple future scenarios and risk type criteria are also recommended to obtain a comprehensive solution for practical decision-making. It is also recommended that the selection of KPIs is carefully made to cover the entire dimensions of future sustainability. In 
addition, inclusion of sensitivity analysis for the most uncertain parameters over their possible domain can be undertaken in future works to obtain robust rankings of intervention strategies.

\section{Acknowledgements}

This work was funded by the 'TRansition to Urban water Services of Tomorrow' (TRUST) project. The authors wish to acknowledge the European Commission for funding TRUST project in the 7th Framework Programme under Grant Agreement No. 265122. The authors also wish to tank Dr Mark Morley (Exeter University) for proofreading the paper and also thank the TRUST project partners including NTNU, Oslo VAV, NTUA and SINTEFF for their collaboration in WP33. The authors wish to thank the anonymous reviewers for making constructive comments which substantially improved the quality of the paper.

\section{References}

Alegre, H., Cabrera Jr, E., Hein, A., Brattebø, H., Framework for Sustainability Assessment of UWCS and development of a self-assessment tool, Project Deliverable D31.1: TRUST report, 2012.

André, F.J., Romero, C., Computing compromise solutions: On the connections between compromise programming and composite programming. Applied Mathematics and Computation, 2008; 195(1) 1-10.

Ashley, R., et al., 2004. Sustainable water services: a procedural guide. London: IWA

Baccini, P., Brunner, P.H., Metabolism of the Anthroposphere. Springer Verlag, Berlin, 1991.

Behzadian K., Z. Kapelan, G. Venkatesh, H. Brattebø, S. Sægrov, E. Rozos, C. Makropoulos: "Quantitative UWS performance model: WaterMet ${ }^{2}$ ", TRUST Project Report, Deliverable D33.2 (https://www.trust-i.net/). , $2014 \mathrm{a}$.

Behzadian K., Kapelan, Z., Venkatesh, G., Brattebø, H., and Sægrov, S. "WaterMet': a tool for integrated analysis of sustainability-based performance of urban water systems”, Drink. Water Eng. Sci.; 2014b; 7, 63-72.

Behzadian K., Kapelan Z. Morley M. "Resilience-based performance assessment of water-recycling schemes in urban water systems", Water Distribution System Analysis, WDSA2014, Procedia Eng., Elsevier; 2014c; 89: 719-726.

Behzadian K., Kapelan, Z., "Modelling Metabolism Based Performance of Urban Water System Using WaterMet ${ }^{2 ",}$ Resources, Conservation and Recycling, Elsevier; 2015; in press.

Butler, D., Davies, J., Urban drainage. Taylor \& Francis 2004.

Cannon, T., Twigg, J., \& Rowell, J., Social vulnerability, sustainable livelihoods and disasters, Report to DFID CHAD and sustainable Livelihoods Support Office, 2003.

Change, Intergovernmental Panel on Climate. Climate change 2007: The physical science basis. Agenda 6.07: $333 ; 2007$.

Chrysoulakis, N., Lopes, M., San José, R., Grimmond, C.S.B., Jones, M.B., Magliulo, V., Klostermann, J.E.M., Synnefa, A., Mitraka, Z., Castro, E. a., González, A., Vogt, R., Vesala, T., Spano, D., Pigeon, G., Freer-Smith, P., Staszewski, T., Hodges, N., Mills, G., Cartalis, C., Sustainable urban metabolism as a link between bio-physical sciences and urban planning: The BRIDGE project. Landsc. Urban Plan. 2013; 112, 100-117.

Collet, L., D. Ruelland, V. Borrell-Estupina, A. Dezetter, and E. Servat. Integrated modelling to assess long-term water supply capacity of a meso-scale Mediterranean catchment. Science of the Total Environment 461, 2013; 528-540.

Esty, D. C., Levy, M. A., Kim, C. H., de Sherbinin, A., Srebotnjak, T., \& Mara, V. Environmental performance index. New Haven: Yale Center for Environmental Law and Policy, 2008, 382

Fagan JE, Reuter MA, Langford KJ. Dynamic performance metrics to assess sustainability and cost effectiveness of integrated urban water systems. Resour Conserv Recycl 2010; 54:719-36.

Fattahi, Parviz, and Saeed Fayyaz. "A compromise programming model to integrated urban water management." Water resources management 24.6 2010; 1211-1227.

$\mathrm{Fu}$, G., D. Butler, and S.T. Khu, The impact of new developments on river water quality from an integrated system modelling perspective, Science of the total environment 407, no. 4, 2009; 1257-1267.

IPCC. In: Eggleston, H.S., Buendia, L., Miwa, K., Ngara, T., Tanabe, K. (Eds.), 2006 IPCC Guidelines for National Greenhouse Gas Inventories. Institute for Global Environmental Strategies, Tokyo, Japan. Prepared by the National Greenhouse Gas Inventories Programme; 2006. 
IWA, Global Trends \& Challenges in Water Science, Research and Management, (Decentralised wastewater management: an overview), Specialist Group on Sanitation and Water Management in Developing Countries of International Water Association; 2012. 73-75

Kennedy, C., Cuddihy, J., Engel-Yan, J., The Changing Metabolism of Cities. Journal of Industrial Ecology 2007; 11(2) 4359.

Kennedy, C., S. Pincetl, and P. Bunje. "The study of urban metabolism and its applications to urban planning and design." Environmental pollution 159.8, 2011; 1965-1973.

Lai, E., S. Lundie, and N. J. Ashbolt. "Review of multi-criteria decision aid for integrated sustainability assessment of urban water systems." Urban water journal 5.4 2008; 315-327.

Loucks, D.P., Van Beek, E., Stedinger, J.R., Dijkman, J.P., Villars, M.T. Water resources systems planning and management: an introduction to methods, models and applications. UNESCO, 2005; 427-457.

Mackay, R., Last, E., SWITCH city water balance: a scoping model for integrated urban water management. Reviews in Environmental Science and Bio/Technology 2010; 9(4) 291-296.

Makropoulos, C.K., Natsis, K., Liu, S., Mittas, K., Butler, D., Decision support for sustainable option selection in integrated urban water management. Environmental Modelling \& Software 2008; 23(12) 1448-1460.

Memon, F.A., Butler, D., Han, W., Liu, S., Makropoulos, C., Avery, L.M., Pidou, M., Economic assessment tool for greywater recycling systems. Proceedings of the ICE-Engineering Sustainability 2005; 158(3) 155-161.

Metcalf and Eddy, "Wastewater Engineering Treatment and Reuse", Fourth edition, McGraw Hill publisher, 2003; $155-163$.

Mitchell, V.G., Diaper, C., UVQ User Manual: (urban water balance and contaminant balance analysis tool), Version 1.2, CMIT Report No. 2005-282. CSIRO 2010.

Morley M., K. Behzadian, Z. Kapelan, R. Ugarelli, Decision Support System for Metabolism-based Transition to Urban Water Systems of Tomorrow, IWA, IWA World Water Congress \& Exhibition, Lisbon Portugal; 2014.

Morley M., D. Vitorino, K. Behzadian, R. Ugarelli, Z. Kapelan, S.T.Coelho, M. Céu Almeida, Decision Support System for the Long-Term City Metabolism Planning Problem, IWA, Proceeding of IWA Cities of the Future Conference, TRUST2015, Mulheim Germany; 2015.

Mouri G, Oki T. Modeling the catchment-scale environmental impacts of wastewater treatment in an urban sewage system for $\mathrm{CO}_{2}$ emission assessment. Water Science Technology 2010; 62(4):972-83.

Nair, S., George, B., Malano, H. M., Arora, M., \& Nawarathna, B. Water-energy-greenhouse gas nexus of urban water systems: Review of concepts, state-of-art and methods. Resources, Conservation and Recycling 2014; 89: 1-10.

Rossman, L. A., EPANET 2: users manual, US Environmental Protection Agency, 2000.

Rozos, E., Makropoulos, C. Source to tap urban water cycle modelling. Environmental Modelling \& Software 2013 ; 41 139150.

Rossman, Lewis A. Storm water management model user's manual, version 5.0. US Environmental Protection Agency, 2010.

Sahely, Halla R., Christopher A. Kennedy, and Barry J. Adams. "Developing sustainability criteria for urban infrastructure systems." Canadian Journal of Civil Engineering 32.1 2005; 72-85.

Savic, D., J. Bicik, M.S. Morley, A. Duncan, Z. Kapelan, S. Djordjević, E.C. Keedwell. "Intelligent Urban Water Infrastructure Management." Journal of the Indian Institute of Science 93, no. 2 2013; 319-336.

Shah, Sameer H., and Robert B. Gibson. "Large dam development in India: sustainability criteria for the assessment of critical river basin infrastructure." International Journal of River Basin Management 11.1 2013; 33-53.

Sušnik, J., Lydia Vamvakeridou-Lyroudia, D. Savić, and Z. Kapelan. Integrated System Dynamics Modelling for water scarcity assessment: Case study of the Kairouan region." Science of the Total Environment 440, 2012; 290-306.

Todini, E.. Looped water distribution networks design using a resilience index based heuristic approach. Urban Water Journal 2000; 2, 115-122.

Venkatesh, G., Sveinung Sægrov, and Helge Brattebø. Dynamic metabolism modelling of urban water servicesDemonstrating effectiveness as a decision-support tool for Oslo, Norway. Water research 2014; 61, 19-33.

Venkatesh, G., S. Sægrov, H. Brattebø, K. Behzadian, Z. Kapelan. Metabolism-modelling approaches to long-term sustainability assessment of urban water services. submited to Urban Water Journal, 2015.

Villarroel Walker, R., M. B. Beck, J. W. Hall, R. J. Dawson, and O. Heidrich. The energy-water-food nexus: Strategic analysis of technologies for transforming the urban metabolism. Journal of environmental management 141, 2014; 104 115. APA

Ward, S., Memon, F.A., Butler, D. Performance of a large building rainwater harvesting system. Water Res 46(16), 2012; 5127-5134.

Willuweit, Lars, and John J. O'Sullivan. "A decision support tool for sustainable planning of urban water systems: Presenting the Dynamic Urban Water Simulation Model." Water research 47.20, 2013; 7206-7220.

Zeleny, M.. Compromise Programming. In: Multiple Criteria Decision Making, Cochrane and M. Zeleny (Editors), . University of South Carolina Press, : Columbia, South Carolina 1973. 